\title{
GAIN STABILITY MEASUREMENT TECHNIQUES \\ FOR CALORIMETER PHOTOTUBES
}

\author{
C. R. Kerns \\ May 13, 1975
}

\section{INTRODUCTION}

Gain variation in phototubes may occur as a result of many factors. Some of these are: time $^{2}$, temperature, 15,22 magnetic field ${ }^{2}$, counting rate ${ }^{3}, 4,6,9$ and several others which are hard to predict and control $6,7,16,17$.

Because of these gain variations, it may be necessary to test each phototube which is anticipated for use in a calorimeter in order to reject those whose gain shift would result in insufficiently accurate results.

\section{TESTING METHODS}

It has been noted by other observers' that two components of gain shift manifest themselves: (1) a long term gradual shift in gain, and (2) an immediate shift when the tube is first subjected to high counting rates. With this in view, two separate testing methods were set up to investigate gain shift. 
TEST SET UP

Figure 1 shows a block diagram of the long term method. A chopped DC light (1 second on, 4 seconds off) was arranged to illuminate a pair of phototubes mounted in an enclosure (dark box). The light repetition rate and duty cycle were chosen to closely match the actual operating conditions to which the phototubes would be subjected in the beam at the Fermi National Accelerator Laboratory. One of the tubes was so connected and biased that it was a photodiode and merely collected the initial photoelectrons (gain of 1). Its use was that of a monitor to record and display the long term light stability. The second tube (the one under test) saw the same light source greatly attenuated by neutral density filters. The two phototubes drove parallel inputs on a dual track chart recorder to enable long term measurements of the tube under test. Any drift of the light source is recorded by the photodiode and the photomultiplier data may be renormalized via the diode data. Several runs were made at various selected light levels thus enabling the photomultiplier to be "exercised" over a range of average anode currents.

Figure 2 shows a block diagram of a different arrangement which records the immediate gain shifts over a range of various light levels. In this test, two light sources were simultaneously directed at the phototube under test. The previously described (on 1 sec. off 4 sec.) light source was used to adjust the phototube average anode current thus simulating various counting rates to which the phototube may be exposed. In addition, a fast, stable light pulser was flashed at the phototube. From the test 
set up diagram (Fig. 2) one sees that the phototube output is split into two components. The fast pulse component is capacitively coupled and terminated into a linear amplifier to drive a pulse height analyzer. The other component is directly coupled, to complete the DC path. A IK termination at the scope provides the convenient transfer function of one Millivolt/microamp of average anode current from the phototube.

The external routing feature of the PHA is utilized to allow the pulses collected during "I sec. light on time" to be stored in a different quadrant of memory than those pulses collected during "4 sec. light off". Thus the two spectra collected may be superimposed for inspection of gain shift as seen in Fig. 3 .

\section{RESULTS}

Data was recorded for 5 different RCA $6342 \mathrm{~A}$ phototubes. Test resuits of these tubes are shown in Fig. 4. No attemps were made to separate the various possible drift sources.

In addition, one tubes data was recorded at two different gain settings $\left(6 \times 10^{5}\right.$ and $\left.1.5 \times 10^{5}\right)$ with light levels adjusted to achieve the same selected anode currents, i.e., the gain was dropped a factor of 4 and the light level increased a factor of 4. Test results of this "gain change run" are shown in Fig. 5 . 
ROUTING SIGNALS

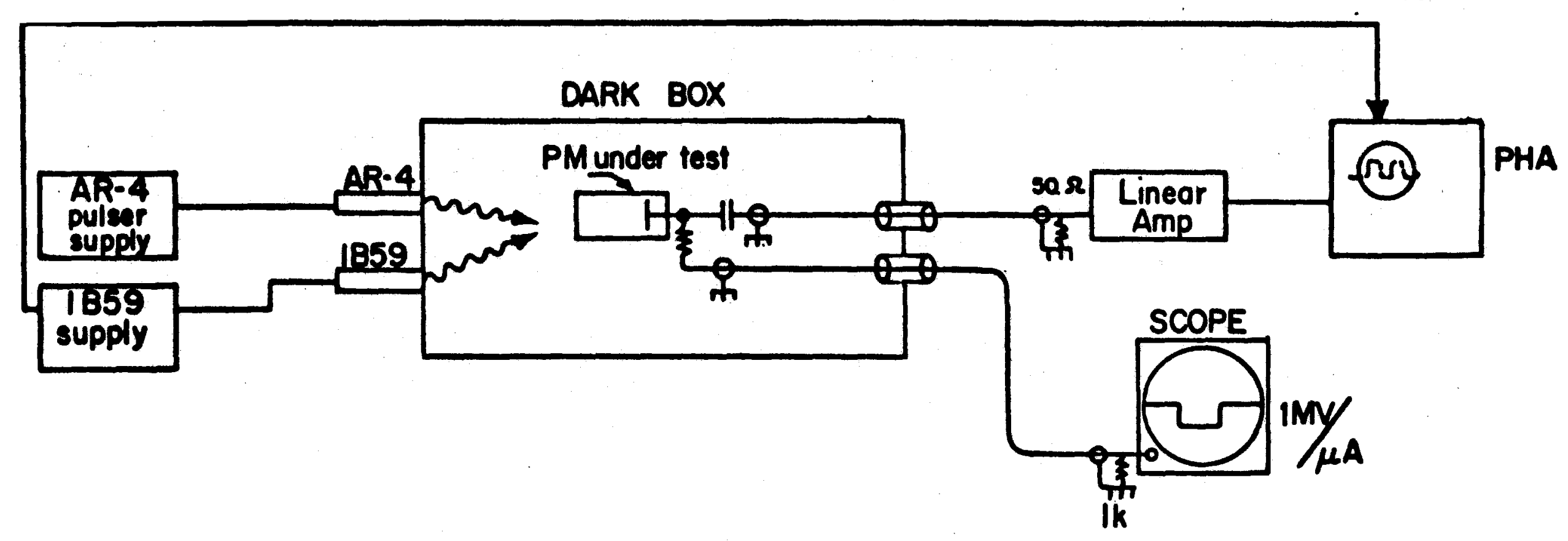

PHOTOTUBE GAIN STABILITY TEST SETUP 


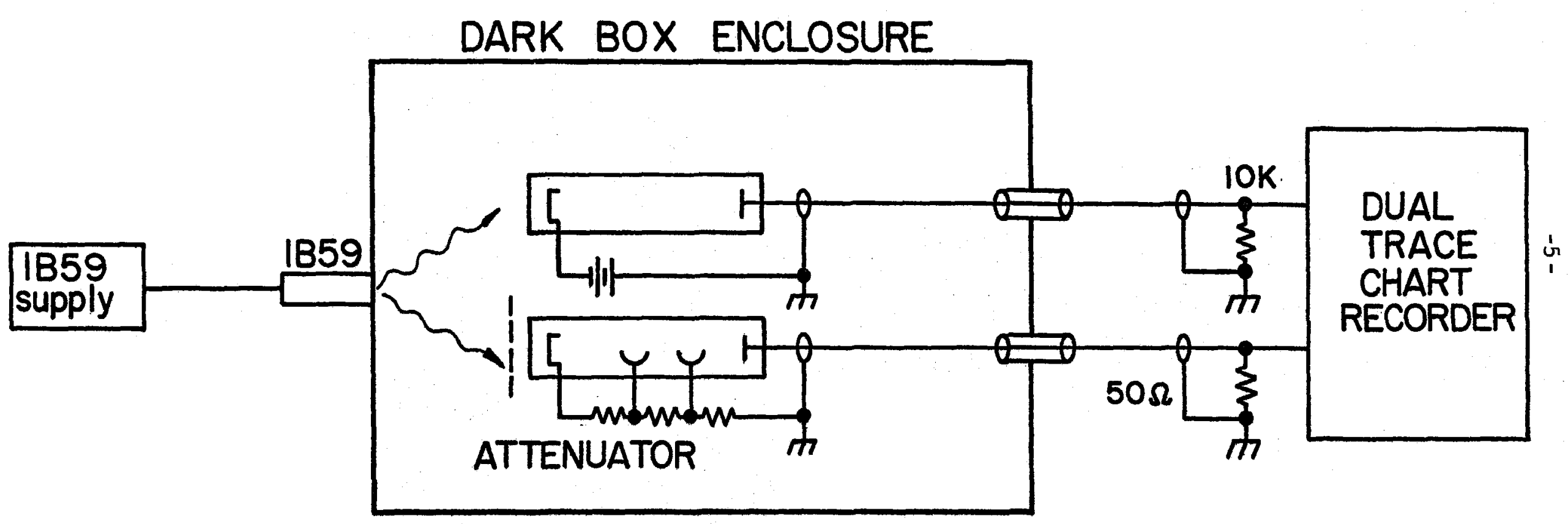

LONG TERM STABILITY TEST SETUP

Fig. 2

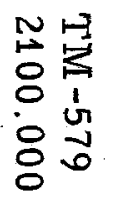



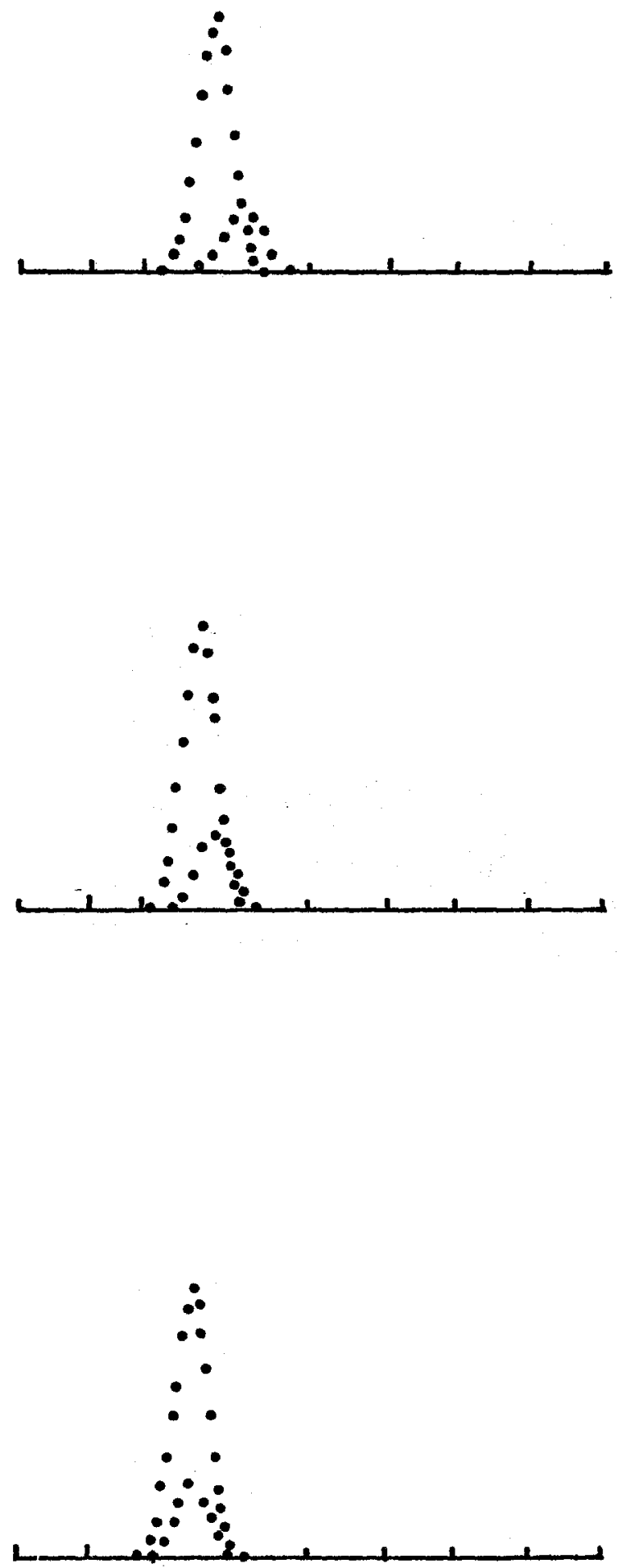

Fig. 3 


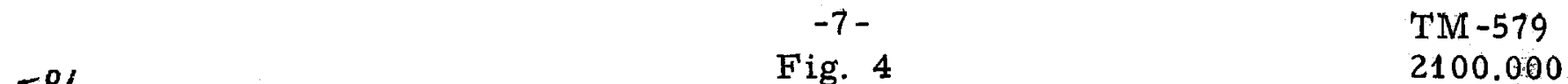

$5 \%$

Fig. 4
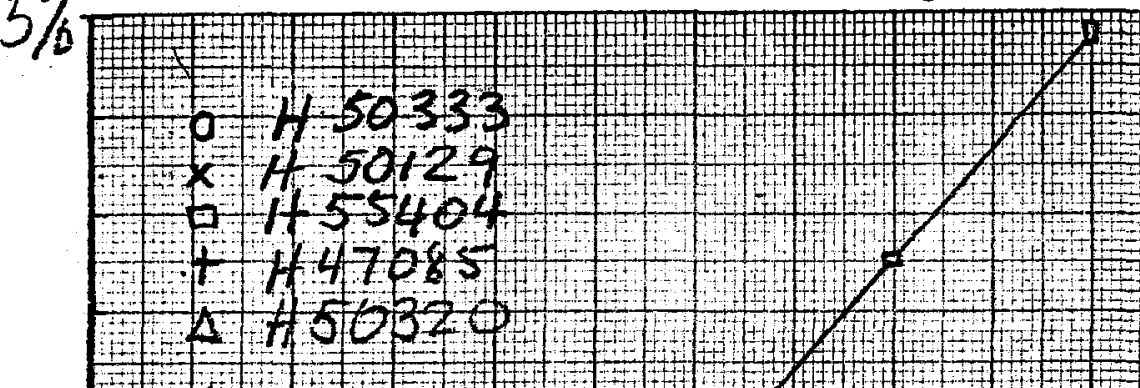

\section{Gan Shaf \\ 63421}

$4 \%$
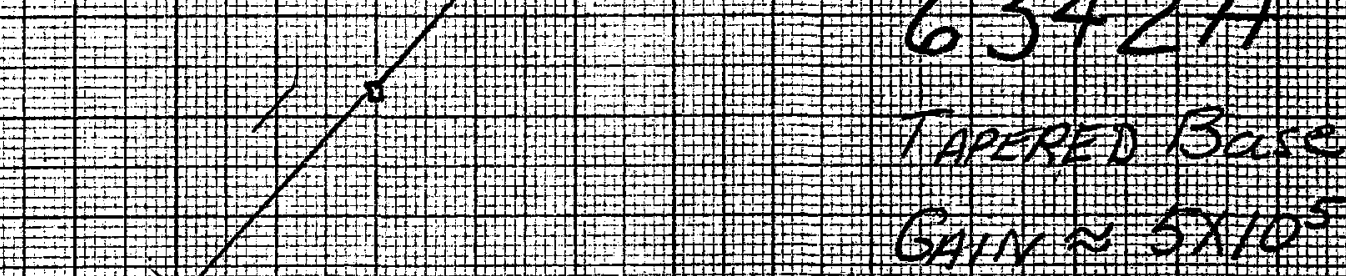

$3 \%$
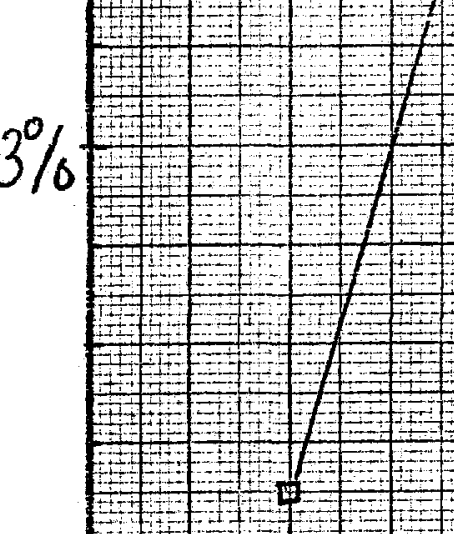

22
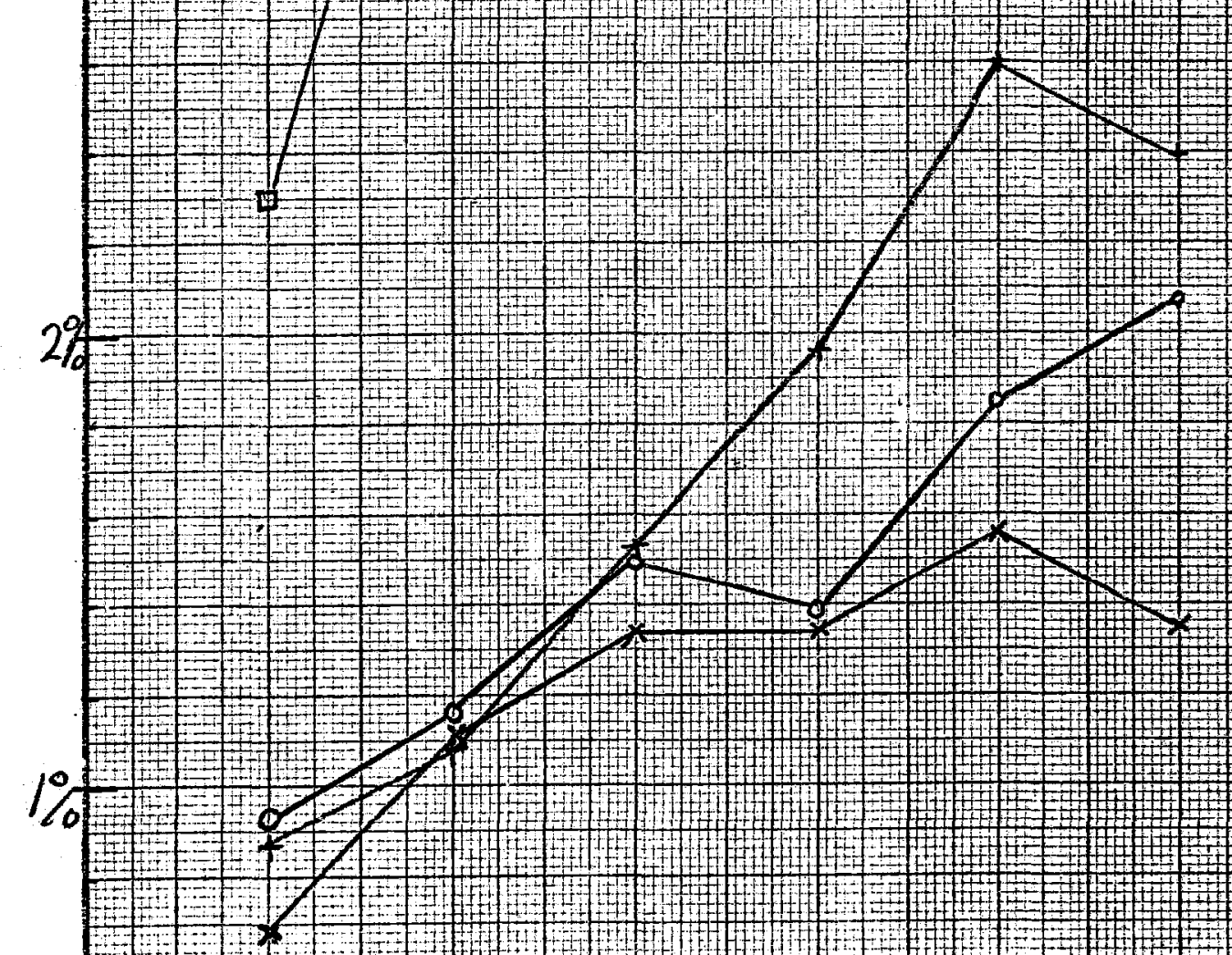

\begin{tabular}{ll}
\hline 10 \\
\hline
\end{tabular}

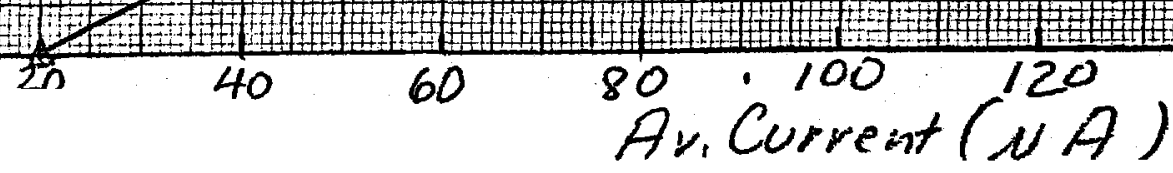




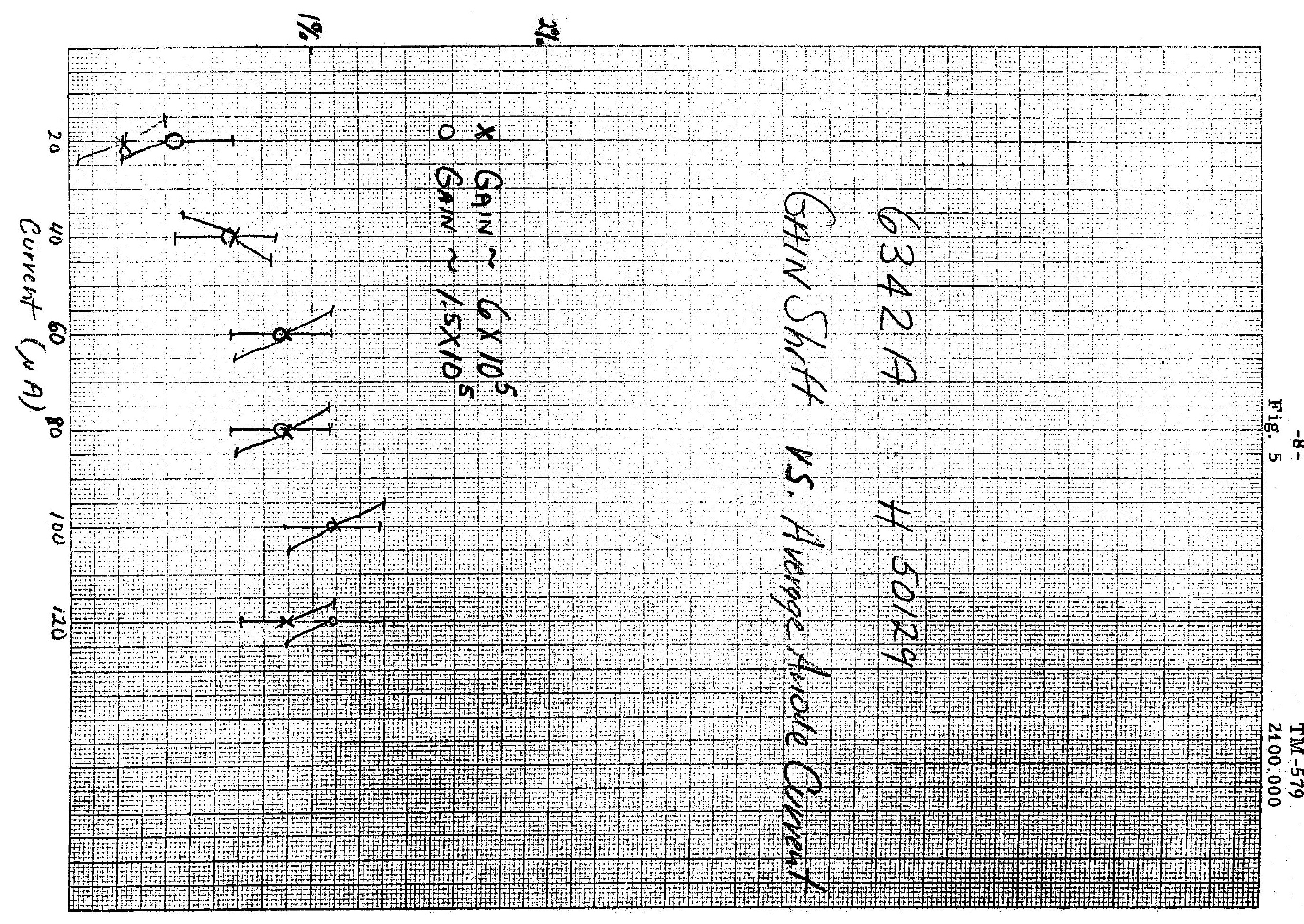




\title{
BIBLIOGRAPHY ON PHOTOMULTIPLIER GAIN INSTABILITY
}

\author{
Prepared for Fermilab Workshop on Calorimetry \\ C. R. Kerns \\ Physics Department \\ May 9, 1975
}

Gain Shift

1) The proceedings of the Scintillation Counter Symposium, published as special volumes of IRE Transactions on Nuclear Science, provide a great deal of photomultiplier information and applications.

2) "Basic Performance Characteristics. Stability", in RCA Photomultiplier Manual (Harrison, N.' M., RCA Electronics Components, 1970), p. 49.

3) Bell, P. R. , Davis, R. C., Bernstein, W., Pulse-Height Variation in Scintillation Counters, Rev. Sci. Instr. 26, 726 (1955).

4) Caldwell, R. L., Turner, S. E. , Gain Variation of Photomultiplier Tubes, Nucleonics 12, 47 (1954).

5) Cantarell, I., Properties, Mechanism, and Experimental Reduction of Effects of the Dependent Field Emission of Photomultiplier Tubes, Puerto Rico Nuclear Center, Mayaguez, Puerto Rico. PRNC 32.

6) Cantarell, I. and Almodovar, I., Fatigue in Photomultiplier Tubes An Effect of the Malter Type, Puerto Rico Nuclear Center, Mayaguez, Puerto Rico (1963). Nucl. Instrum. Methods 24, p. 353-57.

7) Cantarell, I. and Macias, A., Time-Dependent Schottky Emission in Photomultiplier Tubes, Puerto Rico Nuclear Center, Puerto Rico Institute of Mod. Sci. Radiation Instruments and Sources, p. 418.

8) Cathey, L., Fatigue in Photomultipliers, IRE Trans. Nuclear Science, NS-5, p. 109-14 (1958).

9) Covell, D. F. and Euler, B. A., "Gain Shift Versus Counting Rate in Certain Multiplier Phototubes", USNRDL-TR-521, U. S. Naval Radiological Defense Laboratory, San Francisco(1961).

10) Engstrom, R. W., Stoudenheimer, R. G., Glover, A. M., "Production Testing of Multiplier Phototubes", Nucleonics 10, 58 (1952).

11) Husain, Tahir, Fatigue Effect in Photomultiplier, Physics Department, Government College, Lahore, West Pakistan, 1963. 
12) Keene, J. P., Fatigue and Saturation in Photomultipliers, Paterson Laboratories, Christie Hospital and Holt Radium Institute, Manchester 20, England, Rev. Sci. Instrum. 34, No. 11 (1963).

13) Khlebnikov, N. S. and Sinitsyn, P. A. "Fatigue of Antimony-Cesium Photocathodes", Zh. Tekhn. Fiz. 10, 1913 (1940).

14) Linden, B. R., Schenkel, F. W., Jr., Snell, P. A., The Development of Photomultipliers for Scintillation Counting, IRE Transactions on Nuclear Science, NS-7, pp. 61-65, June-September 1960.

15) Lontie-Bailliez, M. and Messen, A., L'Influence de la Temperature sur les Photomultiplicateurs, Centre de Physique Nucleaire, Universite de Louvain.

16) Malter, L., Letters to the Editor, "Anomalous Secondary Electron Emission. A New Phenomenon", Phys. Rev. 49, 478 (1936).

17) Malter, L., "Thin Film Field Emission", Phys, Rev. 50, 48 (1936).

18) Marshall, F. H., Coltman, J. W., Hunter, L. P., "The Photomultiplier X-Ray Detector", Rev. Sci. Instrum. 18, 504 (1947).

19) Miyake, K., "Operation of Cesium-Antimony Phototubes Under High Light Level", Rev. Sci. Instrum. 32, 929 (1961).

20) Murray, R.- B. and Manning, J. J., "Response of End-Window Photomultiplier Tubes as a Function of Temperature", IRE Trans. Nucl. Sci., NS-7, No. 2-3, 80 (1960).

21) Wilson, I. N., Photomultiplier Fatigue. Paper 5. 11, Proceedings of the Sixth Tripartite Instrumentation Conference, Chalk River, Ontario, April 20-24, 1959, Part 5: Radiation. AECL-805.

22) Young, A. T., Temperature Effects in Photomultipliers and Astronomical Photometry, Applied Optics 2, 51 (1963).

Photocathodes

1) Bailey, K. F., Photocathode Fatigue of L-24 PM Head Due to High Intensity Light Pulses, Electronics Engineering Department, Livermore, California, LER 454-7, February 26, 1963.

2) Condas, G. A., Techniques for Evaluating the Commercial Photocathode, University of California, UCRL-6740, Rev. I.

3) Schaetti, N. and Baumgartner, W., "The Behavior of Cs-Sb Photocathodes at Various Temperatures", Helv. Phys. Acta 24, 614 (1951).

4) Spicer, W. E., Wooten, F., Photoemission and Photomultipliers, University of California, UCRL-7149. 
Gain Stabilization Techniques

1) Ageno, M. and Felici, C., Photomultiplier Gain Stabilization Circuit, Physics Laboratory, Instituto Superiore di Sanita, Rome, Italy, Vol. 34, No. 9 (1963).

2) Haun, S. and Kamke, D., Ein Universelles Verfahren Zur Stabilisierung von Szintillations-Spektrometer Anordnungen, Physikalisches Institut der Universitat Marburg/L (1960).

3) Kerns, Q. A. and Tusting, R. F., Constant-Amplitude Light-Flash Generator for Gain Stabilization of Photosensitive Systems, University of California, UCRL-10895.

4) Marlow, K. W. , A System for Stabilizing the Gain of a Scintillation Spectrometer, U. S. Naval Research Laboratory, Washington, DC, (1961).

5) Valekx, F. P. G., Direct Current Stabilization of Scintillation Counters Used with Pulsed Accelerators, Fysisch Laboratorium der Rijksuni versiteit, Utrecht, 1960.

Phototube General Survey Articles

1) Koosman, J. G. , Radioactive Tracer Study of a Phatomultiplier Manufacturing Process, Du Mont Laboratories, Division of Fairchild Camera and Instrument Corporation.

2) Linden, B. R., Five New Photomultipliers for Scintillation Counting, Nucleonics, Vol. 11, No. 9, September 1953, pp. 30-33.

3) Linden, B. R., Snell, P. A., Rutherford, R. E., Development of Du Mont Photomultiplier Tubes, RIB-16, October 1956.

4) Pietri, G. , Present State of Research and New Developments at the Laboratories d'Electronique et de Physique Appliquees (L. E. P) in the Field of Photomultiplier Tubes, Laboratories d'Electronique et de Physique, Paris, France.

5) Sharpe, J., Photomultipliers Document, Ref. No. CP 5306, 1961. 